\title{
A LEGITIMIDADE DO DIREITO NO CONTEXTO DOS PROCESSOS DE VALIDAÇÃO DISCURSIVA E DA DEMOCRACIA
}

\author{
Marcella Coelho Andrade ${ }^{1}$
}

\begin{abstract}
Resumo
O presente artigo, através de uma metodologia teórica e comparativa, analisa o tema da legitimidade do direito, com foco nos processos de validação discursiva e nos espaços de formação do discurso diante do princípio da Democracia. Para abordagem da legitimidade do ordenamento jurídico são utilizados os pontos de vista de Max Weber e Jürgen Habermas, em razão das nuances trazidas pelos referidos autores a respeito do tema. A respeito da ação comunicativa também é feita uma breve abordagem da influência do conceito de poder comunicativo, de Hannah Arendt, no pensamento Habermasiano. Delineiam-se, ainda, os alicerces da Teoria Discursiva do Direito e seus critérios de legitimação, bem como o alcance da razão comunicativa diante do discurso jurídico, paralelamente ao tema da democracia. Conclui-se que os procedimentos dialógicos de elaboração da norma são essenciais para os sistemas democráticos atuais, sobretudo tendo em vista a configuração pluralista das sociedades modernas, mas é essencial a constante avaliação dos espaços de participação existentes, sob uma perspectiva de potencialidade de participação, para que o procedimento discursivo alcance seu intuito de promover normas racionalmente instituídas.
\end{abstract}

Palavras-chave: Legitimidade do direito. Legalidade. Democracia. Agir comunicativo.

\section{THE LEGITIMACY OF LAW IN THE CONTEXT OF DISCURSIVE VALIDATION PROCESSES AND DEMOCRACY}

\begin{abstract}
This article, through a theoretical and comparative methodology, analyzes the theme of the legitimacy of the law, focusing on the discursive validation processes and on the spaces of discourse formation against the principle of Democracy. In order to approach the legitimacy of the legal system, the views of Max Weber and Jürgen Habermas, due to the nuances brought by the authors on the subject. With regard to communicative action, a brief approach is also given to the influence of Hannah Arendt's concept of communicative power on Habermasian thought. The foundations of the Discursive Theory of Law and its criteria of legitimation, as well as the scope of communicative reason before legal discourse, parallel to the theme of democracy, are also outlined. It is concluded that the dialogical procedures of elaboration of the norm are essential for the current democratic systems, especially in view of the pluralist configuration of modern societies, but it is essential to constantly evaluate the existing spaces of participation, from a perspective of potential participation, so that the discursive procedure reaches its aim of promoting rationally instituted norms.
\end{abstract}

Keywords: Legitimacy of law. Legality. Democracy. Act communicative.

\footnotetext{
${ }_{1}$ Advogada,Bacharela em Direito pela Universidade Federal de Juiz de Fora (2016) e Mestra em Ciências Sociais pela Universidade Federal de Juiz de Fora (2019).
} 


\section{Introdução}

Uma questão importante para as Ciências Sociais é procurar compreender como a sociedade não se desmancha em planos individuais de ação, e quais são os mecanismos aptos a produzir uma integração social que coordene tais planos. O Direito é concebido como um sistema de legitimação do ordenamento jurídico uma vez que cria um efeito de obediência consentida dos indivíduos, que tem sua liberdade limitada pela lei. Trata-se, portanto, de um instrumento de controle e integração social.

Assim, tal integração só se torna possível por intermédio de mecanismos sociais, e, conforme Habermas (1989, P. 41), "a linguagem o meio apto para promover tal fenômeno de maneira estável e legítima". Sendo assim, para ele, somente por meio da comunicação é que se torna possível estabelecer o entendimento racionalmente desenvolvido entre os indivíduos, coordenando suas ações. Desse modo, entende que a legitimidade normativa está fulcrada na teoria do agir comunicativo. Em contrapartida, Max Weber compreende que a legitimidade está intrinsecamente ligada à legalidade, ao sistema positivado.

Ocorre que é possível que as pretensões dos enunciados linguísticos outrora concebidos como aceitos sejam criticadas por parte dos envolvidos na ação social. Nesses casos, conforme a teoria Habermasiana, para que não se corra o risco de desintegração social, recorre-se ao agir comunicativo, denominado discurso. No discurso busca-se o argumento mais racional, e, sendo assim, o agir comunicativo orienta-se na pretensão ao entendimento, à produção de consenso.

Todo esse debate torna-se ainda mais relevante se colocada em face das atuais sociedades pluralistas e do Princípio Democrático. Conforme Luiz Moreira (1999, p. 125), "a suposição da coerção fática, que as normas jurídicas exercem, deve comprovar sua validade a partir de um processo legislativo em que, pela correição procedimental, constitui-se enquanto norma que efetiva a liberdade". Para que o Direito seja assim compreendido é necessário que haja um consenso em torno de sua obrigatoriedade, e isso só é possível diante de uma esfera pública apta a produzir o agir comunicativo.

Por essas razões, é que torna pertinente investigar a questão da autoridade e da legitimidade do direito e do discurso, analisando os diferentes modelos de legitimação trazidos por Max Weber e por Jürgen Habermas, especialmente no que diz respeito aos conceitos de legitimidade e legalidade. Importa, também, trazer a 
lume os conceitos de poder em Max Weber e em Hannah Arendt, pois, há uma influência direta dessa discussão na teoria Habermasiana, especialmente em relação à questão das legitimações modernas. (HABERMAS, 1977).

Por meio dessas observações e análises torna-se possível perquirir a respeito da legitimidade do direito, seus fundamentos e suas relações com o princípio democrático e com os espaços de comunicação estabelecidos em razão deste. Tornando-se viável, ainda, averiguar a efetividade dos processos de validação discursiva no contexto das sociedades atuais e quais os possíveis limites por elas enfrentados.

\section{Os processos de legitimação do ordenamento jurídico e do direito em Max Weber e Jürgen Habermas}

Dado o exposto torna-se necessária a investigação da legitimidade do ordenamento jurídico e do direito em face do papel de instrumento de integração que estes representam para o melhor funcionamento da sociedade. Para tanto, procura-se destrinchar os diferentes modelos de legitimação trazidos em Weber e Habermas, notadamente quanto aos conceitos de legitimidade e legalidade, que são distintos nos referidos autores.

Em Weber (1999, p. 188), a legitimidade de um ordenamento social pode ocorrer a partir de fontes diversas, fornecendo o fundamento para a legalidade. Esta, em contrapartida, depende da lei escrita e de instituições competentes para implementá-la, como através dos quadros administrativos. Há, portanto, uma sequência natural entre legalidade e legitimidade na teoria Weberiana.

Habermas, fazendo uma reviravolta nesse pensamento, argumenta no sentido que a legalidade cria, nas sociedades modernas, a legitimidade da ordem, desde que respeitados alguns critérios democráticos. Desse modo, a legitimidade, em Habermas, depende da ordem legal, da institucionalização do poder democrático e do direito discursivo. Para que a ordem legal possua validade social, e seja assim legítima, é preciso que as suas leis, as normas da administração pública e as formas de controle tenham sido elaboradas pelas vias argumentativas.

Nas palavras de Habermas (1977, p. 145),

o princípio da democracia destina-se a amarrar um procedimento de normatização legítima do direito. Ele significa, com efeito, que 
somente podem pretender validade legítima as leis jurídicas capazes de encontrar o assentimento de todos os parceiros do direito, num processo de normatização discursiva.

Weber partindo de um conceito positivista de legitimidade, em sua obra Economia e Sociedade, utiliza-se do conceito de legitimidade para distinguir os tipos puros de dominação, quais sejam, o racional, o tradicional e o carismático. (WEBER, 1979, p. 128). Vê-se, assim, que a legitimidade é usada como um critério essencial para diferenciar os tipos puros de dominação. No tipo de dominação tradicional a obediência é validada pela tradição ou pelo costume. Já a dominação carismática é um tipo peculiar, pois leva em conta características "sobrenaturais", como, o heroísmo, o carisma ou a vocação - critérios que apelam para a emoção, e não critérios racionais. Por fim, o domínio legal/racional está fundamentado na validade dos regulamentos estabelecidos na lei. Trata-se da obediência a uma regra, e não a uma pessoa. Nesse sentido,

obedece-se não à pessoa em virtude de seu direito próprio, mas à regra estatuída, que estabelece ao mesmo tempo a quem e em que medida se deve obedecer. Também quem ordena obedece, ao emitir uma ordem, a uma regra: à "lei" ou "regulamento" de uma norma formalmente abstrata. (WEBER, 1979, p. 129)

O fato de que nenhum dos tipos, ideais costuma existir historicamente em forma realmente pura não deve impedir a fixação do conceito na forma mais pura possível. Isso, pois, a tipologia sociológica oferece ao trabalho histórico empírico a vantagem de poder dizer, no caso particular de uma determinada forma de dominação, em que medida ela se aproxima de um destes tipos, além de trabalhar com conceitos razoavelmente inequívocos. (WEBER, 1999. p. 141).

Dentre os modelos de legitimidade mencionados o foco do presente trabalho centraliza-se no tipo de dominação racional, de Weber, em contraposição com o modelo Habermasiano, para - qual a legitimidade do ordenamento jurídico pauta-se na racionalidade a ser atingida mediante processos de validação discursiva. Em linhas gerais, legitimidade e legalidade, na teoria Weberiana, estão diretamente associadas. Assim, as normas são legais e legítimas se obedecem ao procedimento determinado pelo ordenamento jurídico. A legalidade justificaria a dominação 
do direito nas sociedades jurídicas modernas, de forma autônoma, uma vez que se funda no procedimento formal de produção/alteração das normas jurídicas.

Conforme Weber (1999, p. 146), "O desenvolvimento da administração burocrática constitui a célula germinativa do moderno Estado ocidental". Sendo a administração burocrática a forma mais racional do ponto de vista técnico-formal, ela é um tipo puro de dominação legítima, tornando-se indispensável para as necessidades da administração de massas. Segundo o autor (1999, p. 147) a administração burocrática é a dominação em virtude de conhecimentos, sendo este o seu caráter fundamental especificamente racional. Assim, 0 grande instrumento de superioridade da administração burocrática é o conhecimento profissional, e o espírito da burocracia racional concentra-se no formalismo e tendência dos funcionários a uma execução materialmente utilitarista de suas tarefas administrativas.

O fundamento da dominação racional apontado por Weber é de especial importância, pois segundo o autor é nele que está a estabilidade da dominação legal própria da atualidade. Desse modo, seria a crença na legalidade que resultaria na submissão dos sujeitos a esta forma de dominação, caracterizada pela positivação do direito e por um quadro administrativo burocrático. Ao fundar a legitimidade da dominação legal na legalidade surge a indagação do que é legal.

Dessa maneira, Weber desloca o óbice da legitimidade do direito positivado para a procedimentalização pelo qual o direito é produzido. Em última análise, a pedra de toque da legitimação do ordenamento jurídico moderno, de acordo com o pensamento Weberiano, reside na crença em um dado procedimento que proporcione a identificação do direito. Assim, a legitimidade é colocada no interior da legalidade. O direito se auto-legitima, portanto, por um procedimento jurídico formal próprio, dispensando qualquer fundamentação externa a ele. Essa é uma característica que diferencia a dominação legal-racional dos outros tipos de dominação, que dependem de fatores externos ao direito, tais como a tradição e o carisma.

Já para Habermas há uma relação entre legalidade e legitimidade que caracteriza o Estado Democrático de Direito, mas refuta-se a relação coincidente entre esses conceitos. Jürgen Habermas passa a abordar a relação intersubjetiva como base da racionalidade, o que representa uma importante mudança de paradigma, escapando dos vícios do positivismo jurídico. Para que 
a legalidade produza legitimidade é preciso que ela mesma seja legítima, pressupondo a certeza de um fundamento racional que transforma em válido todo o ordenamento jurídico.

Habermas (2012) analisa o pensamento Weberiano, questionando a legitimidade do próprio procedimento, pois para ele a crença na legalidade não pode gerar legitimidade por si só, apenas por estar estabelecida no direito positivo. Afinal, assentar a legitimidade do direito no procedimento não soluciona o problema, apenas o desloca para o próprio procedimento. Nesse ínterim, referido autor investiga esse tipo de legitimidade proposto por Weber para a dominação legal, questionando como o surgimento de legitimidade pode ser possível a partir da mera legalidade. Segundo Habermas (2014, p. 99),

A resposta do positivismo jurídico consiste no recurso a uma regra fundamental arbitrariamente adotada ou que se tornou hábito, a título de premissa fundamentadora da validade. [...] Em contraposição a isso, a teoria do discurso atribui ao próprio procedimento da formação democrática da opinião e da vontade a força geradora da legitimidade.

Em consonância com a teoria Habermasiana, a legitimidade não pode ser estudada desvinculada da própria democracia moderna. Dadas tais premissas, um ordenamento só será válido, se além de legal e legítimo, suas normas e leis forem produzidas pela democracia, com a participação de todos, mediante princípios discursivos e racionais exigidos para se constituir uma ordem normativa. A legitimidade do direito só pode ser dada da perspectiva do participante, no contexto de uma sociedade envolvida e atuante na esfera política.

Embora tenha consciência de que haja fundamentos racionais para que se instituam procedimentos para a elaboração da norma, Max Weber acredita que uma vez que este procedimento exista os indivíduos não mais se preocupam com o seu fundamento racional. Isso leva a uma espécie de tradicionalização do procedimento, o que demonstra certa incoerência em sua teoria e é objeto de crítica em Habermas. Para este o que dá caráter legítimo a uma decisão legal é a confiança na racionalidade do ordenamento jurídico, permanecendo como fundamental a questão da racionalidade permeando todo o direito moderno. 
Assim, em Habermas, a adesão pelos envolvidos a uma norma pressupõe a participação destes em sua elaboração. Apenas desse modo é que ganha sentido a questão da autoridade das normas jurídicas. Porém, trata-se de uma potencialidade de participação, havendo uma tensão entre a comunidade ideal e a comunidade real de comunicação. A comunidade real de comunicação conhece diversas limitações, atreladas a ideologias e violência, obstando a produção livre do convencimento e de entendimento.

Indagam-se quais seriam, portanto, as limitações dos discursos jurídicos diante do modelo procedimentalista da democracia. De antemão é possível vislumbrar que em sociedades complexas e pluralistas como a nossa, uma participação atual e efetivamente irrestrita no diálogo é impossível. Daí recorre-se à regra da maioria, que se mostra como um instrumento democrático. Porém, as decisões tomadas por intermédio dessa regra da maioria não podem excluir do discurso qualquer grupo social, nem tomar decisões irreversíveis.

É a partir dessas premissas, e repensando a questão da fundamentação racional que Habermas busca elaborar um novo conceito de legitimidade. Conceito este que é capaz de compreender o fenômeno como um todo, superando os vícios trazidos pelo positivismo jurídico. Desse modo, torna-se necessário compreender qual a dimensão dessa participação e quais os espaços efetivamente existentes para o desenvolvimento do agir comunicativo nas sociedades pluralistas e democráticas atuais, o que será objeto de análise no ponto quatro do presente trabalho.

\section{A influência do conceito de poder de Hannah Arendt na teoria habermasiana}

Hannah Arendt propõe um modelo de poder comunicativo, poder este instituído como uma capacidade humana de unir-se a outros e atuar em assentimento com eles. O fundamental em sua concepção é a formação de uma vontade comum, orientada pra o entendimento recíproco, livre de violência e coerção. Ademais, para ela, o poder existe porque pertence a um grupo e existe enquanto este conservar-se unido. Max Weber, partindo do modelo teleológico da ação, define o poder como a possibilidade de impor a própria vontade a comportamento alheio, dentro de uma relação social. Em suma, 
Max Weber defined as the possibility of forcing one's will on the behavior of others. Hannah Arendt, on the contrary, understands power as the ability to agree upon a common course of action in unconstrained communication. (HABERMAS, 1977, p.3)

Assim, no conceito Weberiano, um sujeito, ou um grupo de pessoas, se propõe a um objetivo e escolhe os meios apropriados para concretizá-lo. O sucesso fica na dependência do comportamento do outro sujeito, e por isso devem existir meios que induzam o comportamento desejado, que é o poder. Por meio do modelo da teoria da ação Weber considera os atores orientados para o próprio sucesso, e não para o entendimento de todos os participantes.

Hannah Arendt, e posteriormente Habermas, em uma visão mais moderna, concebem que esse caso reserva-se ao conceito de violência. Para Hannah Arendt o poder requer uma esfera pública livre de repressões, onde a liberdade é um direito assegurado à comunidade. Para ela, o poder se origina nas experiências de trocas linguísticas feitas entre pessoas em igual nível de racionalidade. Só podendo surgir o poder em estruturas da comunicação não coercitiva. Os meios de coerção e os discursos persuasivos são associados, de outro lado, à violência.

Nesse sentido, de acordo com a teoria do discurso Habermasiana, a legitimidade advém do procedimento de formação democrática da opinião e da vontade. Para tanto o autor estabelece algumas premissas, quais sejam, a inclusão simétrica de todos os envolvidos ou de seus representantes nesses processos; e o entrelaçamento da decisão democrática com a troca discursiva e sem coerções quanto às informações e tomadas de posição. Para Habermas (2014, p. 100),

\begin{abstract}
A fonte normativa da legitimidade brota, segundo essa concepção, da combinação da inclusão de todos e do caráter deliberativo de formação da sua opinião e da sua vontade. A ideia de constituição livre e conduzida pela razão de uma vontade comum [...] se expressa, portanto, no vínculo de inclusão e deliberação.
\end{abstract}

Já para Max Weber, a dominação constitui-se como um dos elementos mais importantes da ação social. Contudo, nem toda ação social é caracterizada como dominação, e a dominação é apenas um tipo especial de poder. "Dominação, no sentido muito geral de poder, isto é, de possibilidade de impor ao 
comportamento de terceiros a vontade própria, pode apresentase nas formas mais diversas". (WEBER, 1999, p. 188) O autor divide o domínio em três tipos puros, tipos ideais, utilizados para a análise do desenvolvimento dos sistemas políticos, conforme já minudenciado na seção anterior.

Importante lembrar que Weber (1999) elabora essa tipologia de dominação diante de um Estado Alemão inserido num processo de burocratização crescente, de racionalização administrativa, que não conseguia se desvincular da esfera do domínio do tipo tradicional. Desse modo, o consenso encontrado nas formas de dominação não advém de uma ação coletiva em situação de igualdade, o que leva a Weber à conclusão que a dominação é um caso especial de poder.

A visão de Hannah Arendt é ainda diversa da posição Weberiana, pois ela faz uma distinção entre força e poder. A força estaria atrelada à força física de um indivíduo ou à força humana. $O$ poder, em contrapartida, seria algo que surge entre os homens, quando estes se juntam para iniciar algo. Ademais, o poder só se mantém se o pacto original for preservado e perseguido. É esse pacto que dá legitimidade às autoridades constituídas, portanto, para Arendt o poder dá origem ao governo.

A concepção de Max Weber, como já ressaltado, parte de um modelo teleológico de ação, onde o sucesso da ação depende da capacidade do ator de influenciar um comportamento desejado aos demais sujeitos. Assim, o conceito de poder em Weber poderia ser qualificado em Arendt como uma espécie de "violência".

Hannah Arendt, em sua análise sobre o poder comunicativo, investiga processos históricos e sociais que se desenvolvem sem a participação dos envolvidos interessados. Apesar de consistente, a teoria de Hannah Arendt possui limitações. Habermas ressalta que esse modelo de poder comunicativo pode ocasionar algumas incoerências, quando aplicado em sociedades modernas. Para ele

o conceito do poder comunicativamente produzido, de H. Arendt, só pode transformar-se num instrumento válido se o desvincularmos de uma teoria da ação inspirada em Aristóteles. H. Arendt faz remontar o poder político exclusivamente à práxis, a fala recíproca e à ação conjunta dos indivíduos (...). Com isso, entretanto, H. Arendt tem que pagar o preço de: a) excluir da esfera política todos os elementos estratégicos, definindo-os como violência; b) de isolar a política dos contextos econômicos e sociais em que está embutida 
através do sistema administrativo; c) de não poder compreender as manifestações da violência estrutural. (HABERMAS, 1993, p. 110-111).

Ao pensar nos espaços participativos a autora não concede grande relevância ao lugar social em que os indivíduos estão. Assim, é necessário perceber que Arendt equivoca-se ao estabelecer que apenas a criação de espaços institucionais é suficiente para a participação política. Afinal, é preciso levar em conta outros pressupostos para analisar a participação de um indivíduo na esfera pública, como aspectos materiais, sociais e culturais.

Sendo assim, a autora concebe o poder como uma faculdade de alcançar um acordo quanto à ação comum, em um espaço público livre de violência, partindo para outro modelo de ação, que é o modelo da ação comunicativa. O pilar fundamental do poder não pode residir na instrumentalização de uma vontade alheia para os próprios fins, mas sim na formação de uma vontade comum. Desse modo, o fenômeno do poder deve estar orientado para o entendimento recíproco. A partir desse conceito de poder, e apesar das críticas feitas a ele, Habermas busca reconstruir a relação interna entre direito e política, sendo que, para produzir a legitimidade, devem existir mecanismos comunicativos na esfera pública.

\section{Os processos de validação discursiva no contexto da democracia}

Uma vez compreendida a ideia de que nas sociedades pluralistas e democráticas atuais os processos de validação discursiva são de importância fulcral, passa-se a entender a dimensão do princípio democrático em face do novo conceito de legitimidade, fundado na racionalidade. Apenas na democracia ocorre a coexistência de diferentes projetos de vida sem ferir as exigências de justiça e de segurança, necessárias à integração social. A legitimidade das decisões tomadas por maioria, dentro das argumentações discursivas, não deriva da maioria em si mesma, mas da racionalidade do argumento pressuposto pela decisão assim tomada.

A legitimidade do ordenamento jurídico passa, em Habermas, a depender de uma legitimação feita pelos próprios cidadãos, através da formação de espaços de validação discursiva, perpassando pela racionalidade do argumento. Nesse sentido: 
O surgimento da legitimidade a partir da legalidade não é paradoxal, a não ser para os que partem da premissa de que o sistema do direito tem que ser representado como um processo circular que se fecha recursivamente, legitimando-se a si mesmo [...] A compreensão discursiva do sistema dos direitos conduz o olhar para dois lados: de um lado, a carga de legitimação dos cidadãos desloca-se para os procedimentos de formação discursiva da opinião e da vontade, institucionalizados juridicamente; de outro lado, a juridificação da liberdade comunicativa significa também que o direito é levado a explorar fontes de legitimação das quais ele não pode dispor. (grifei) (HABERMAS, 1977, p. 168)

Dessa maneira, a fundamentação das normas jurídicas deve ser feita, no contexto de sociedades pluralistas, através de um procedimento neutro e imparcial, na busca do melhor argumento. Em face ao princípio democrático é que as normas podem pretender-se com legitimamente válidas, tendo em vista a possibilidade de contar com o consentimento de todos os cidadãos em processos legislativos que, por sua vez, também devem ser constituídos legalmente.

A consagração do Estado Democrático de Direito objetiva incentivar uma participação dos cidadãos no processo de tomada de decisões políticas. Apesar das críticas acerca da efetividade dos modos de participação previstos nas cartas constitucionais nos contextos democráticos atuais, nota-se uma crescente busca pelos espaços e meios de participação dos indivíduos no cenário político-social. Ademais, torna-se importante reconhecer que a revolução digital e os meios de comunicação representam um avanço no entrelaçamento comunicativo e na mobilização da sociedade civil, o que nos leva a abandonar uma imagem institucionalmente estagnada do Estado democrático de direito. Nas palavras de Habermas (2014, p. 98-99),

a fluidificação comunicativa da política se presta, como chave sociológica, para entender o conteúdo realista do conceito de política deliberativa. [...] A construção do Estado constitucional se deixa conceber como uma rede de discursos formadores da opinião e da vontade, juridicamente institucionalizados.

A participação efetiva dos indivíduos nesses processos de validação discursiva vai de encontro com a ideia de Estado Democrático de Direito, autorizando a tomada de decisões consideradas a partir do interesse de todos os envolvidos no cenário político e social. Tudo isso deve, porém, estar pautado no 
equilíbrio decorrente dos processos discursivos com abertura à prevalência do argumento mais racional, pois só dessa maneira estar-se-á diante de um verdadeiro Estado Democrático.

O princípio democrático acolhe postulados da teoria democrática representativa, com a estruturação de processos que ofereçam aos cidadãos efetivas possibilidades de participar nos processos de decisão, tais como a presença de órgãos representativos, eleições periódicas, pluralismo partidário, separação dos poderes, dentre outros. A boa democracia é aquela que tem um processo deliberativo livre (com uma comunicação sem coerção), onde a legitimidade é produzida em um processo comunicativo na esfera pública. Assim, para Habermas (1997. p. 53),

O conceito do direito moderno - que intensifica e, ao mesmo tempo, operacionaliza a tensão entre facticidade e validade na área do comportamento - absorve o pensamento democrático, desenvolvido por Kant e Rousseau, segundo o qual a pretensão de legitimidade de uma ordem jurídica construída com direitos subietivos só pode ser resgatada através da força socialmente integradora da 'vontade unida e coincidente de todos' os cidadãos livres e iguais. (grifei)

As leis passam a depender do discurso prévio entre todos os envolvidos (e não do direito natural, como antes concebido), ou pelo menos dos diretamente afetados pela ação legislativa. Por vezes a norma pode perder a sua legitimidade, ou seja, tornar-se injusta, não representando mais o argumento racional obtido por meio da comunicação dos indivíduos. Pode, ainda, admitir-se falha, quando na verdade nunca tenha expressado verdadeiramente a vontade discursiva, e nesses casos deve ser modificada.

Afinal, não haveria sentido um ordenamento jurídico impassível de modificação, seja ela em razão da perda da sua legitimidade ou da sua falibilidade, pois isso significaria um descrédito nos processos discursivos ou uma crença exacerbada e cega no procedimento de produção de normas, sendo que nesse último caso de aproximaria muito do positivismo jurídico trazido por Max Weber. Assim, qualquer processo decisório de formação ou modificação da normatividade jurídica somente pode ser legitimado se precedido do diálogo democrático e conciliador, o qual supõe a efetiva participação de todos os envolvidos. 
Reconhece-se na Teoria Habermasiana que uma característica muito importante do Direito reside na capacidade deste em reunir elementos prescritivos, mas abertos à revogação, afinal "o que é válido precisa estar em condições de comprovar-se contra as objeções apresentadas factualmente". (HABERMAS, 1997, p. 56) Nesse tocante, há uma mudança de paradigmas no modo em que o ordenamento jurídico é concebido, uma vez que os cidadãos passam a desempenhar uma posição de coautores do sistema jurídico, e não meros destinatários, como outrora.

A legitimidade do direito só pode acontecer quando os próprios cidadãos produzem as leis e os códigos que vigoram em seu ordenamento, segundo a ideia do próprio sistema democrático. Desse modo, conforme Habermas, o Direito não deve ser considerado uma instância externa aos indivíduos, mas parte integrante destes. Nesse sentido, quanto àqueles que se posicionam estrategicamente contrários ao consenso geral e não estão dispostos a adotar as prescrições estabelecidas coletivamente, o direito está autorizado a atuar através da coerção, na busca da efetivação da norma racional estabelecida no contexto da ação comunicativa. Nas suas palavras:

o direito ao mesmo tempo legítimo e coercitivo coloca os cidadãos diante da escolha de seguir as normas vigentes ou por interesse próprio, na expectativa de sanções, ou por respeito à lei, tendo em vista o procedimento da positivação democrática do direito. (HABERMAS, 2014, p. 106)

Sendo assim, é preciso reconhecer que a legitimidade de uma ordem jurídica não pode garantir, por si só, uma obediência ao direito sem ter como pano de fundo a ameaça estatal. Contudo, é importante notar, ainda que sem o devido aprofundamento, que o direito brasileiro caminhou em sentido diverso do direito europeu, uma vez que este se diferenciou com planos próprios de regulação, havendo um reconhecimento da legitimidade da autoridade supraestatal como medium jurídico.

Em razão do exposto, nota-se que o procedimento legislativo não confere por si só autoridade absoluta à norma, pois até mesmo em contextos de espaços de comunicação a norma produzida por se tornar inválida ou ser injusta. Para a teoria da ação comunicativa, transformada em teoria discursiva do Direito, não existe uma esfera que a priori forneça padrões de conduta 
considerados inquestionáveis. Isso, pois, a norma jurídica apenas se institui como legítima se expressar como vontade discursiva dos envolvidos, não se baseando ou fundamentando em razões apenas fundadas na filosofia da consciência ou na metafísica.

Porém, a teoria discursiva do direito sofre críticas no que se refere à suposta impossibilidade fática de efetivação de espaços de diálogo que forneçam um procedimento discursivo onde prevaleça o melhor argumento. Apesar disso, não se pode duvidar que a situação ideal de fala nada mais é do que um critério de argumentação discursiva, ou, dito de outro modo, um critério normativo, e, portanto, crítico. Afinal, em sociedade tão plurais, com tanta diversidade e tão populosas, trata-se de uma mera distribuição simétrica de oportunidades de participação política, como nos processos eleitorais e nos processos de efetivação dos atos de fala.

Dessa maneira, é possível perceber que a situação ideal de fala diverge da situação real de fala, mas aquela é sempre operante, uma vez que é uma condição de possibilidade ao entendimento. Idealizar uma situação de fala plena constitui-se numa antecipação contrafática, algo inviável até mesmo nas democracias mais avançadas, em razão das ressalvas já delineadas. A formação discursiva da normatividade jurídica é inerente e implícita na noção de Estado Democrática de Direito, consagrando o Princípio Democrático.

Apesar disso, a comunidade real de comunicação não pode estar muito afastada da comunidade ideal de comunicação, ou seja, os espaços discursivos devem ser minimamente suficientes para o alcance do argumento racional, capaz de promover normas legítimas e aptas a reger a vida dos cidadãos. Só dessa maneira é que se estará diante de um discurso realmente condizente com o princípio democrático e apto o bastante para promover a legitimidade do ordenamento jurídico.

\section{Considerações finais}

Dado o exposto, compreende-se que o discurso é o meio capaz de produzir de modo mais duradouro a integração social, pois, no discurso os falantes levantam pretensões de validade que são criticadas por outros falantes, possibilitando mudanças, revisões e adequações constantes. Dessa maneira é que se torna possível obter êxito na busca do argumento mais racional. Portanto, chega-se à conclusão que nas legitimações modernas o 
pensamento Habermasiano mostra-se mais apto a promover a interação dos indivíduos do que a legitimação positivista adotada por Max Weber, uma vez que compreende o acontecimento como um todo, e não se centraliza na pura e simples legalidade.

Nota-se, também, a influência do conceito de poder comunicativo de Hannah Arendt no pensamento de Jürgen Habermas, principalmente no que se refere à necessidade de mecanismos comunicativos livres aptos a promover o diálogo e legitimar racionalmente o ordenamento jurídico e o próprio direito. Essa particularidade do poder residir na formação de uma vontade comum, que diverge da ideia de Weber, é vital em Habermas, e em sua teoria da ação comunicativa, indo ao encontro, ainda, do contexto das legitimações atuais e do princípio democrático.

O princípio do discurso refere-se aos procedimentos de elaboração da norma onde se pressupõe um procedimento dialógico, o que é essencial em sistemas democráticos. Nesse sentido, e, sobretudo tendo em vista uma sociedade pluralista, os argumentos podem ser revistos e reavaliados diante de novos argumentos que resistam de maneira melhor aos então concebidos. Cumpre salientar a necessidade da constante avaliação dos espaços de participação efetivamente existentes, dentro de uma perspectiva de possibilidade de participação, para que o procedimento discursivo cumpra e alcance seu objetivo de promover normas racionalmente instituídas.

Afinal, em consonância com as ideias expostas, para um governo manter sua legitimidade é importante que se valorize 0 cumprimento das normas, o diálogo, a participação dos indivíduos e a valorização do discurso como um elemento norteador e assegurador do processo democrático. Além, é claro, de garantir a legitimidade política e a estabilidade social, política e econômica de uma sociedade, bem como um ordenamento jurídico idôneo para nortear a vida dos cidadãos.

\section{Referências}

HABERMAS, Jürgen. Consciência Moral e agir comunicativo. Tradução: Guido Antônio de Almeida. Rio de Janeiro: Tempo Brasileiro, 1989.

Direito e Democracia: entre facticidade e validade. Volume I

e II. Tradução: Flávio Beno Siebeneichler. Rio de Janeiro: Tempo Brasileiro, 1997.

Hannah Arendt's communications concept of power. Social

Research, n.44, v.1, 1977. 
Na esteira da tecnocracia: pequenos escritos políticos XII. Tradução Luiz Repa. $1^{a}$ ed. São Paulo: Editora UNESP, 2014.

. O conceito de Poder de Hannah Arendt. In: FREITAG, Barbara; ROUANET, Sérgio Paulo (orgs.). Habermas - sociologia. Coleção Grandes Cientistas Sociais. Tradução de Barbara Freitas. São Paulo: Ática, 1993.

Teoria do agir comunicativo. São Paulo: Martins Fontes, 2012.

MOREIRA, Luiz. Fundamentação do direito em Habermas. Belo Horizonte: Mandamentos, 1999.

WEBER, Max. Economia e sociedade: fundamentos da sociologia compreensiva. Brasília: Editora Universidade de Brasília, 1999.

Os três tipos de dominação legítima, in Gabriel Cohn (org.). Weber.

São Paulo: Editora Ática, Coleção Grandes Cientistas Sociais, 1979. 